the effect of the different aspects of what may be called polarised cowls or terminals, i.e. cowls or terminals the action of which is different according to their position with regard to the direction of the wind. One of the most conspicuous is that of a cowl of the same shape as the torpedo air extractor now so much in use on railway carriages. From the numbers given, the apparatus is clearly much more effective when the wind crosses the opposed cones than when it passes along the cones and through the ring, and this difference of action is definitely characteristic of the two positions of the cowl.

Towards the end of the period of its labours the committee began to approach the question in more academic or philosophical fashion. Experiments with smoke were tried to see how cowls and terminals really acted. The committee was thus led to test the effect of successive variations of the number, size, position and arrangement of different modifying elements, such as a flange at the rim of the orifice or at a measured distance from it, a set of "feathers" arranged round the orifice and "louvre" bands or caps above it. A series of experiments to test the effect of the variation of a single element was carried out on single days and the results plotted in curves for the single varying elements. Here we have as results only galvanometer readings for different batteries, so to speak, but for batteries varying only in a single particular, and from such information effective inferences can be drawn about the action of the battery. These results afford the best material in the report for the scientific study of the action of cowls. It still remains only material, and requires working up with due regard to the theoretical considerations referred to. But some practical results follow directly. For example, a flange surrounding the orifice of the pipe diminishes the aëromotive force produced by wind passing over it, and if sufficiently extended practically an$\mathrm{n}$ :hilates the flow. It is nnt by any means impossible that an examination of these curves may lead to further investigation of the laws of flow through tubes under the action of passing wind. It is a subject which presents all the difficulties of the corresponding electrical problems, with some added in consequence of the inertia of the moving fluid, but it is of great practical as well as theoretical importance, and the report will have done good service if it attracts attention to the further study of the subject from this aspect.

One of the most amazing facts about the history of science in the last century is the little progress made in our knowledge of pneumatics compared with the advances in our knowledge of the flow of electricity, which still borrows its language for practical purposes from the older and now almost neglected study of the flow of fluids. The theoretical development of electricity can be attributed to Faraday's experimental investigation of the laws of electromagnetic induction. The flow of air along pipes in consequence of wind passing over the top may fairly be regarded as a case of pneumatic induction. The experiments of the cowl committee, if they have not succeeded in classifying these inductive effects into laws, have reopened the study of the subject, and at least give evidence that it is not the fulness of experimental knowledge that has dissuaded the intellects of the students of our laboratories from its investigation.

W. N. SHAW.

\section{GOLD IN INDIA.}

NDIAN gold is attracting the attention of the Geological Survey of India. In NATURE for May 9, I9OI we directed attention to Dr. F. H. Hatch's report on the Kolar gold-field in Mysore. We have now received reports on the gold-fields of Wainád, by Mr. H. H. Hayden and Dr. Hatch, and on some auriferous localities in north Coimbatore, by Mr. Hayden (Mem. Geol. No. I 685 , VOL. 65$]$
Survey, India, vol. xxxiii. part ii. 190r.) These districts lie to the south of Mysore. The extraordinary discrepancy between reports made on various properties of Wainád by mining experts and the actual results subsequently obtained have justified independent investigations on the part of the Indian Government. It is recorded that in I880 numerous companies, having an aggregate capital of more than four million pounds, were floated on the London market; of these only three companies retain their properties, and no work has been done for a number of years. The question to be solved was whether improved modern methods might render it possible to revive the gold-mining industry in the area. Dr. Hatch's report is, however, unfavourable. Dealing specially with two mines, he finds that ore does not occur in payable quantity, and he is unable to recommend further prospecting. Mr. Hayden gives an interesting historical sketch of the gold-mines, and describes in some detail the geological features of the district. The country-rock is in most cases biotite gneiss; this has been affected by a series of parallel fissures which run obliquely to the direction of the foliation, and in these fissures the vein-material was deposited. : Pyrites proved to be the chief source of the gold, but the richer orebodies are small irregular patches, not of sufficient extent to be of material value.

$\mathrm{Mr}$. Hayden remarks that there are few auriferous areas in India, poor as well as rich, that have not at some period or other been exploited by the natives; but the fact that gold was obtained in sufficient quantity to cover the expenses and leave a margin of profit, does not in itself justify the belief that a good margin of profit would be obtained if modern methods of working were adopted. Many of the reefs were probably mined by forced labour or by slaves. Thus one of the Wainád reefs, which was, perhaps, worked more extensively than any other, has given, from nearly 200 samples, an average yield of about two pennyweights of gold to the ton of ore. In Coimbatore there are numerous old native workings for gold, but they are, as a rule, small and unimportant, and the ore-bodies are either very thin or barren. Further prospecting, however, appears to be advisable in this district.

\section{NOTES.}

THE attendance of the Prince of Wales at the meeting of the Royal Society on Thursday last is an event which we have pleasure in recording. His Royal Highness was formally admitted as a Fellow of the Society, and remained throughout the meeting. At the close of the proceedings he was invited by the president to address the meeting, and in response he said :"Mr. President, my lords and gentlemen,-It gives me very great pleasure to have been able to come here to-day and to be formally admitted as a Fellow of this ancient and distinguished society. But, as you conferred the honour of Fellowship upon me some eight years ago, I really ought to apologise for not having presented myself before. I can only say I am indeed proud that my name should be added to those on your illustrious. roll, which has been inscribed by nearly every Sovereign since the reign of Charles II., and by all the most distinguished men of science since those days, such as Wren, Newton, Davy, Faraday, Darwin, and many others. I would wish to offer my sincere thanks to Sir William Crookes for his most interesting lecture, which I am sure we have all listened to with great pleasure. If I may be allowed to do so, I should like to con. gratulate him on his power of treating such an abstruse question (for I must confess that the title rather alarmed me) so as to make it intelligible and attractive to those who, like myself, unfortunately cannot lay claim to much scientific knowledge. But, while fully, realising how far beyond my reach this 